\title{
Treatment with Standard and Low Dose of Conjugated Equine Estrogen Differentially Modulates Estrogen Receptor Expression and Response to Angiotensin II in Mesenteric Venular Bed of Surgically Postmenopausal Hypertensive Rats
}

\author{
Priscila Xavier Araujo, Tiago Januário Costa, Cinthya Echem, Maria Aparecida de Oliveira, \\ Rosangela Aparecida Santos-Eichler, Lucas Giglio Colli, Francesc Jiménez-Altayó, \\ Elisabet Vila, Eliana Hiromi Akamine, Ana Paula Dantas, Graziela Scalianti Ceravolo, \\ and Maria Helena Catelli de Carvalho \\ Department of Pharmacology, Institute of Biomedical Sciences, University of São Paulo, Brazil. (P.X.A., T.J.C., C.E., M.A.O., \\ R.A.S.E., L.G.C., E.H.A., M.H.C.C.); Department of Physiological Sciences, State University of Londrina, Londrina, Brazil. \\ (G.S.C.), Facultat de Medicina, Departament de Farmacologia, Terapèutica i Toxicologia, Institut de Neurociències, Universitat \\ Autònoma de Barcelona, Bellaterra, Spain. (F.J.-A., E.V.); Group of Atherosclerosis and Coronary disease, Institut Clinic del \\ Torax, Institut d'Investigaciones Biomédiques August Pi I Sunyer (IDIBAPS), Barcelona, Spain. (A.P.D.)
}

Received February 1, 2017; accepted April 21, 2017

\begin{abstract}
Standard hormone therapy for menopausal women [conjugated equine estrogen (CEE) $0.625 \mathrm{mg}$ ] has been associated with increased risk of venous thrombosis. Regimens containing a lower CEE dose $(0.30 \mathrm{mg})$ have been used clinically to decrease side effects of supraphysiologic doses of estrogen. In this study, we determined the effects of standard (SD) and low dose (LD) of CEE on venular function in ovariectomized (OVX) spontaneously hypertensive rats (SHR). Contractions by angiotensin-II (Ang-II $10 \mu \mathrm{M})$ in perfused mesenteric venular bed were markedly increased in OVX $(21.5 \pm 1.3 \mathrm{mmHg})$ compared with Sham (14.7 $\pm 1.1 \mathrm{~mm} \mathrm{Hg}, P<0.05)$. CEE-SD did not modify Ang-II responses in OVX, whereas CEE-LD restored Ang-II contraction to Sham levels. Endothelial nitric oxide synthase (eNOS) inhibition by L-NAME increased Ang-II contractions in Sham and CEE-LD and was without effect in venules of OVX SHR and CEE-
\end{abstract}

SD. In OVX there was decreased NO generation in association with diminished eNOS phosphorylation and increased $\mathrm{O}_{2}^{-}$generation in the venular wall. CEE-LD reverted the deleterious effects of ovariectomy. Although CEE-SD augmented eNOS phosphorylation in OVX, it was unable to increase NO levels, probably owing to its inability to reduce $\mathrm{O}_{2}^{-}$. Distinct effects by CEE-SD and CEE-LD parallel the differential modulation of Ang-II and estrogen receptors. Compared with Sham, CEE-LD increases Ang II receptor type 2, whereas CEE-SD modified ER $\beta$ expression in the venous bed. Interestingly, both CEE doses increased G protein-coupled estrogen receptor in OVX. Our data suggest that estrogen dose is an important factor for venous function. Although CEE-LD reversed deleterious effects of OVX, CEE-SD showed null effects despite its ability to increase eNOS activity.

\section{Introduction}

For decades, postmenopausal women have been using hormone therapy (HT) worldwide for the relief of menopausal symptoms. The beneficial effects of HT in urogenital atrophy and the prevention of osteoporosis have been well documented by randomized clinical trials (Christiansen et al., 1980;

Research was funded by Coordenação de Aperfeiçoamento de Pessoal de Nível Superior (CAPES0-CAPES/DGU; Grant 269/12); Programa HispanoBrasileño de Cooperación Interuniversitaria (Grant HBP-2011-0054_PC); Red de Investigación Cardiovascular-HERACLES (Grant RD12/0042/0006).

M.H.C.C. G.S.C., A.P.D contributed equally to this work.

https://doi.org/10.1124/jpet.117.240465.
Horsman et al., 1983; Lindsay et al., 1984; Lindsay, 1993; The Writing Group for the PEPI Trial, 1995). In Western countries, oral formulations of conjugated equine estrogen (CEE) represent the most commonly prescribed HT (Steinkellner et al., 2012). However, serious concerns have been raised over the effects of CEE on the cardiovascular health of menopausal women following the release of data from the Women's Health Initiative (WHI) randomized trial (Rossouw et al., 2002) and the Million Women Study (Beral and Collaborators, 2003). Results from these studies prompted many women in the United States to discontinue HT with $\mathrm{CEE}$, and in Europe to practically abandon its use, and to seek

ABBREVIATIONS: Ang-II, angiotensin II; ATR, angiotensin II receptor; $\mathrm{AT}_{1} \mathrm{R}$, angiotensin II receptor type 1; $\mathrm{AT}_{2} \mathrm{R}$, angiotensin II receptor type 2; $\mathrm{CEE}$, conjugated equine estrogen; CEE-LD, low dose of conjugated equine estrogen; CEE-SD, standard dose of conjugated equine estrogen; DAF2, 4,5-diaminofluorescein diacetate; DHE, dihydroethidium; eNOS, endothelial nitric oxide synthase; ER, estrogen receptor; GPER, G protein-coupled estrogen receptor; HT, hormone therapy; L-NAME, NG-nitro-L-arginine-methyl ester; NOS, nitric oxide synthase; OVX, ovariectomy, ovariectomized; ROS, reactive oxygen species; SHR, spontaneously hypertensive rats. 
safer alternatives for treatment of menopausal symptoms (Files et al., 2011; Steinkellner et al., 2012).

CEE comprises more than 10 different forms of estrogens derived from the urine of pregnant mares. The main components are estrone and equilin, with smaller amounts of $17 \alpha$-estradiol, equilenin, $17 \alpha$-dihydroequilin, $17 \beta$-dihydroequilin, $17 \alpha$-dihydroequilenin, and $17 \beta$-dihydroequilenin, and only a minimal level of $17 \beta$-estradiol (see Table 1 ). In addition to CEE, the mixture also contains traces of progestins, androgens, and substances of unknown activity/modes of action (Barton et al., 2007; Bhavnani et al., 2008). As such, the CEE mixture is not considered bioidentical to naturally occurring estrogens in women (i.e., 17 $\beta$-estradiol, estrone, and estriol) and therefore may not provide comparable effects. In fact, studies have shown that CEE effects are markedly lower than $17 \beta$-estradiol depending on cell type or tissue studied (Bhavnani et al., 2008; Novensa et al., 2011).

Other concerns, beside the type of estrogens, have been raised as probable causes of cardiovascular risk by CEE, including its association with medroxyprogesterone, the administration route, duration of treatment, and the administration of supraphysiologic doses of estrogen. With time, the dosage of HT regimens in postmenopausal women has declined progressively, and in the past 10 years the use of lower dose of HT has grown in popularity. At present, the regimens containing $0.30 \mathrm{mg}$ of $\mathrm{CEE}$ are considered low-dose HT (Grodstein et al., 2000; Peeyananjarassri and Baber, 2005). Although the effects of the lower doses of HT have been questioned (Gambacciani et al., 2008), clinical studies have shown beneficial effects comparable to the standard dose of HT with fewer side-effects for postmenopausal women (Peeyananjarassri and Baber, 2005). These studies showed the efficacy of low-dose HT to prevent osteoporosis (Gambacciani et al., 2001; Lindsay et al., 2002; Gambacciani et al., 2003b) and relief of other symptoms associated with menopause (Gambacciani et al., 2003a). However, information on the cardiovascular risk/benefits of low-dose HT is still meager and controversial (Hale and Shufelt, 2015), and there is even less data on the effects of low-dose HT in venules.

Studies using animal models have demonstrated that treatment with oral CEE improves arterial function (Ceravolo et al., 2013) and, therefore, may be beneficial to the cardiovascular system. However, transdermal estrogen (Speroff, 2010) and oral CEE (Peeyananjarassri and Baber, 2005) have also been associated with increased risk of venous thrombosis $(\mathrm{Hu}$ and Grodstein, 2002; Blondon et al., 2014; Smith et al., 2014), suggesting that CEE may display opposing effects in arteries and veins.

The link between estrogen use and venous thromboembolism was identified more than 20 years ago, and extensive literature describes this risk. It has been demonstrated that the risk of venous thromboembolism increases as estrogen dose increases. The most prescribed oral dose of CEE $(0.625 \mathrm{mg})$ leads to supraphysiologic plasma levels of estrogen in both postmenopausal women (Sarrel et al., 1998) and animal models (Costa et al., 2015), which may increase estrogenassociated side effects and contribute to the prothrombotic effects associated with HT. For that reason, there is increasing interest in applying lower-doses of HT in postmenopausal women (Gambacciani et al., 2003a; Peeyananjarassri and Baber, 2005; Zang et al., 2010).
In vitro evidence has increased that angiotensin II (Ang-II) plays a key role in the formation of thrombosis (González Ordóñez et al., 2000; Mogielnicki et al., 2005). Although Ang-II has no direct effect on platelet aggregation, it significantly potentiates platelet-endothelial cell adhesion (Senchenkova et al., 2014); therefore, Ang-II-induced changes in venular responses may be indicative of higher risk of vein thrombosis. In this regard, we sought to determine the effects of estrogen withdrawal (by ovariectomy) and different doses of CEE regimen on mesenteric venular responses to Ang-II and the intrinsic mechanisms involved. We used ovariectomized hypertensive female rats as our established experimental model of surgical menopause resembling postmenopausal hypertension in women.

\section{Methods}

Animals. We used spontaneously hypertensive female rats (SHR) that we ovariectomized (OVX) as an experimental comorbidity model of post-menopause and hypertension in women (Dantas et al., 1999; Fortepiani et al., 2003), on the basis that estrogen deprivation by ovariectomy and post-menopause induces endothelial dysfunction (Pinto et al., 1997; Virdis et al., 2000) and increases blood pressure when compared with healthy and younger premenopausal women (Barton and Meyer, 2009). Twelve-week-old female SHR were obtained from breeding stock of the Institute of Biomedical Sciences of University of São Paulo (ICB-USP). The study was approved by the Ethical Committee for Animal Research of the Institute of Biomedical Sciences, University of São Paulo (Protocol number 145, page 95, book 2 , December 06, 2010). Rats were ovariectomized as previously described (Dantas et al., 1999). Thirty days after ovariectomy, a group of OVX SHR was treated by gavage for 15 days with either a standard dose (SD) of CEE (CEE-SD; Premarin $9.6 \mu \mathrm{g} / \mathrm{kg} /$ day; Pfizer) or a low dose (LD) of CEE (CEE-LD; Premarin .96 $\mu \mathrm{g} / \mathrm{kg} /$ day; Pfizer). To extrapolate standard and low doses of CEE from women to rats, we considered body mass index of postmenopausal women described in the Women's Health Initiative (approximately $65 \mathrm{~kg}$ ) and the standard dose of Premarin ( $0.625 \mathrm{mg} /$ day) used to treat postmenopausal women (Rossouw et al., 2002). Age-matched female SHR in physiologic estrus were used as control (Sham). Physiologic estrus was determined by microscopic evaluation of vaginal smears, as described (Cora et al., 2015).

Tissue Preparation for Immunofluorescence and Measurements of Reactive Oxygen Species and NO Production. Segments of second- and third-order branches of the venular mesenteric bed were dissected free of fat and connective tissues and mounted in optimal cutting temperature (OCT) freezing medium. Cross-sections $(10 \mu \mathrm{m})$ were obtained using a cryostat (Leica, Wetzlar, Germany).

Blood Pressure Measurement. Arterial blood pressure was determined in conscious rats by indirect tail-cuff plethysmography (pneumatic transducer, PowerLab 4/S; AD Instruments, Colorado Springs, CO), as previously described (Ceravolo et al., 2007). Systolic blood pressure was defined as the moment a definitive pulse could be detected. Results were calculated as an average of three consecutives measurements and expressed as millimeters of mercury.

Effectiveness of Ovariectomy and Estrogen Therapy. At the day of sacrifice, rats were anesthetized with sodium thiopental $(50 \mathrm{mg} / \mathrm{kg}$, i.p.), a laparotomy was performed, and the uterus removed and dried for 24 hours in incubator at $37^{\circ} \mathrm{C}$ (dry weight). The results were expressed as milligrams of tissue and normalized by tibia length $(\mathrm{mg} / \mathrm{cm})$. Peripheral blood was collected from abdominal aorta in a glass tube and centrifuged at $3000 \mathrm{~g}, 15^{\circ} \mathrm{C}$ for 15 minutes to obtain the serum. Estrogen concentration was determined using the radioimmunoassay (Siemens Estradiol Coat-A-Count; Siemens Healthcare Diagnostics, Deerfield, IL) according to manufacturer's protocol. 
Mesenteric Venular Bed Perfusion. Isolated perfused mesenteric venular bed preparations were performed as previously described (Warner, 1990; Loiola et al., 2011). Rats were anesthetized with sodium thiopental $(50 \mathrm{mg} / \mathrm{kg}$, i.p.), the mesenteric bed was exposed, a cannula was inserted retrogradely into portal vein, and the vascular mesenteric bed was dissected out. The mesenteric venular bed was perfused using a peristaltic pump (Minipuls 3; Gilson, Middleton, WI) with Krebs-Henseleit solution at $37^{\circ} \mathrm{C}$ in the presence of $95 \% \mathrm{O}_{2}$ and $5 \% \mathrm{CO}_{2}$ for 40 minutes (the first 20 minutes at a constant rate of $2 \mathrm{ml} / \mathrm{min}$ and the remaining time at $4 \mathrm{ml} / \mathrm{min}$ ).

After the equilibration period, $10 \mu \mathrm{M}$ phenylephrine was perfused for 10 minutes [to avoid desensitization of angiotensin II receptor type $1\left(\mathrm{AT}_{1} \mathrm{R}\right)$ ] followed by a bolus injection of angiotensin II (Ang-II) at $10 \mathrm{nM}$ to $10 \mathrm{mM}$ to produce contractile responses. Because significant effects of Ang-II were seen only at $10 \mu \mathrm{M}$, only results at this concentration were considered in this study. Ang-II responses were obtained in the absence or presence of L-NAME (NG-nitro-L-argininemethyl ester, $100 \mu \mathrm{M}$ ), a nitric oxide synthase (NOS) inhibitor. Effects of NOS inhibition were calculated the change between basal (untreated) and stimulated (L-NAME) perfusion pressure ( $\mathrm{mm} \mathrm{Hg}$ ).

Nitric Oxide Production. Basal NO production was measured using 4,5-diaminofluorescein diacetate (DAF-2), a fluorescent marker sensitive to NO. Sections $(10 \mu \mathrm{m})$ were placed on glass slides and incubated at $37^{\circ} \mathrm{C}$ for 30 minutes with DAF-2 (12.5 $\left.\mu \mathrm{M}\right)$ in phosphate buffer (0.01 M, pH 7.4) containing $\mathrm{CaCl}_{2}(0.45 \mathrm{mM})$. Digital images were captured in a microscope (Nikon E 1000; Melville, NY) equipped with epifluorescence. Mean optical density of fluorescence was analyzed using the Image J program (Wayne Rasband, National Institutes of Health) in three different locations of each image.

Reactive Oxygen Species Production. Reactive oxygen species (ROS) production was measured by dihydroethidium (DHE) fluorescence. The $10-\mu \mathrm{m}$ sections were placed on glass slides and incubated for 30 minutes at $37^{\circ} \mathrm{C}$ in a light-protected and humidified chamber with DHE solution ( $5 \mu \mathrm{M})$. Digital images were captured in a microscope (Nikon E 1000) equipped with epifluorescence. Mean optical density of fluorescence was analyzed by a computer system (KS300 software; Zeiss, Oberkochen, Germany) in three different locations of each image and normalized by the area. Specific signal for

TABLE 1

Constituents of conjugated equine estrogens

\begin{tabular}{|c|c|}
\hline CEE & Constituent \\
\hline Estrogens & $\begin{array}{l}\text { Estrone sulfate } \\
\text { Equilinsulfate } \\
17 \alpha \text {-Dihydroequilinsulfate } \\
17 \alpha \text {-Estradiolsulfate } \\
17 \beta \text {-Dihydroequilinsulfate } \\
17 \alpha \text {-Dihydroequileninsulfate } \\
17 \beta \text {-Hydroequileninsulfate } \\
\text { Equileninsulfate } \\
17 \beta \text {-Estradiolsulfate } \\
\Delta 8,9 \text {-Dehydroestronsulfate }\end{array}$ \\
\hline Progestins & $\begin{array}{l}5 \alpha \text {-Pregnane- } 3 \beta, 20 \beta \text {-diol } \\
5 \alpha \text {-Pregnane- } 3 \beta, 16 \alpha, 20 \beta \text {-triol } \\
5 \alpha \text {-Preg-16-en- } 3 \beta \text {-ol-20-one } \\
5 \alpha \text {-Pregnane- } 3 \beta \text {-ol-20-one } \\
\text { 4-pregene-20-ol-3-one-sulfate } \\
3 \beta \text {-Hydroxy-5(10), 7-estradiene } 17 \text {-one-3-sulfate }\end{array}$ \\
\hline Androgens & $\begin{array}{l}5 \alpha \text {-Androstane- } 3 \beta, 17 \alpha \text {-diol } \\
5 \alpha \text {-Androstane- } 3 \beta, 16 \eta \text {-diol } \\
5 \alpha \text {-Androstane- } 3 \beta, 16 \alpha \text {-diol } \\
5 \alpha \text {-Androstane- } 3 \beta \text {-ol, } 16 \text {-one }\end{array}$ \\
\hline Other substances & $\begin{array}{l}5,7,9 \text { (10) Estratriene-3 } \beta, 17 \beta \text {-diol } \\
17 \alpha \text {-Dihydro-delta } 8,9 \text {-dehydroestrone } \\
17 \beta \text {-Dihydro-delta } 8,9 \text {-dehydroestrone } \\
5,7,9,(10) \text { Estratriene-3 } \beta \text {-ol-17-one } \\
\text { 2-Hydroxyestrone } \\
\text { 2-Methoxyestrone }\end{array}$ \\
\hline
\end{tabular}

Barton et al. (2007); Bhavnani et al. (2008).
$\mathrm{O}_{2}^{-}$was determined by treatment with permeable superoxide dismutase (150 IU/ml, 30 minutes). The mechanisms influencing ROS production in the venular wall were determined by pretreatment (30 minutes) with an $\mathrm{AT}_{1} \mathrm{R}$ blocker (losartan, $1 \mu \mathrm{M}$ ), an NADPHoxidase inhibitor (apocynin, $10 \mu \mathrm{M}$ ), and a NOS inhibitor (L-NAME, $10 \mu \mathrm{M})$.

Quantitative Real-Time Polymerase Chain Reaction. Total RNA (tRNA) was isolated from mesenteric venular bed using TRIzol Reagent (Thermo Fisher Scientific, Waltham, MA) per the manufacturer's protocol. RNA quantification was done by spectrophotometry $(260 \mathrm{~nm})$ in NanoDrop (Thermo Fischer Scientific). Reverse transcriptase (RT) reaction was performed in a final volume of $20 \mu \mathrm{l}$ using $2 \mu \mathrm{g}$ tRNA mixed with $0.5 \mu \mathrm{g}$ of oligo(dT) primer, $0.5 \mathrm{nM}$ dNTP, $1 \times$ Moloney murine leukemia virus (MMLV) buffer, $10 \mathrm{mM}$ dithiothreitol, $40 \mathrm{IU}$ of RNAse inhibitor, and $200 \mathrm{IU}$ of MMLV enzyme. Samples were heated at $42^{\circ} \mathrm{C}$ for 50 minutes, $70^{\circ} \mathrm{C}$ for 15 minutes, and kept on ice. Real-time polymerase chain reaction (PCR) was performed in a final volume of $12.5 \mu \mathrm{l}$ containing each oligonucleotide at $0.5 \mu \mathrm{M}$ concentration (Table 2), and 50\% of total volume of GoTaq qPCR Master Mix (Promega, Fitchburg, WI). Real-time PCR reactions were performed using a Corbett Research system (Corbett Life Sciences, Sydney, Australia). The conditions for PCR were as follows: $95^{\circ} \mathrm{C}$ for 2 minutes, 40 cycles of $95^{\circ} \mathrm{C}$ for 15 seconds, and $60^{\circ} \mathrm{C}$ for 1 minute. Expression data were calculated from cycle threshold (Ct) value using $\Delta \Delta \mathrm{Ct}$ method for quantification (Pfaffl, 2001). The $\beta$-actin mRNA was used for normalization and results were analyzed by fold increases relative to the values obtained in Sham group.

Immunofluorescence. Second-order branches of the superior mesenteric vein were fixed with $4 \%$ phosphate buffered paraformaldehyde ( $\mathrm{pH}$ 7.4) for 1 hour and washed in three changes of phosphate buffered saline ( $\mathrm{pH} 7.4)$.) Frozen sections $(20 \mu \mathrm{m})$ were incubated with a rabbit primary polyclonal antibody against ER- $\alpha$, ER- $\beta$, and G protein-coupled estrogen receptor (GPER) (1:50; Santa Cruz Biotechnology, Dallas, TX). After washing, rings were incubated with the secondary donkey anti-rabbit IgG antibody conjugated to CyTM3 (1: 200; Jackson Immunoresearch Laboratories Inc., West Grove, PA). Sections were processed for immunofluorescence staining essentially as previously described (Jiménez-Altayó et al., 2009). Immunofluorescent signals were viewed using an inverted Zeiss LSM 780-NLO confocal laser scanning microscope. Quantitative analysis of fluorescence was performed with ImageJ (Wayne Rasband, National Institutes of Health). The average intensity was measured in at least two rings of each animal, and the results were expressed as arbitrary units.

Western Blotting. Frozen mesenteric venules were homogenized and protein extract obtained with lysis buffer containing $1 \%$ of Triton-X, $100 \mathrm{mM}$ Tris $\mathrm{pH} 7.4,100 \mathrm{mM}$ sodium pyrophosphate, $100 \mathrm{mM}$ sodium fluoride, $10 \mathrm{mM}$ EDTA, $10 \mathrm{mM}$ sodium orthovanadate, $2 \mathrm{mM}$ phenylmethyl sulfonyl fluoride, and $0.01 \mathrm{mg} / \mathrm{ml}$ of protease inhibitor. Samples were centrifuged at $10,000 \mathrm{~g}$ for 30 minutes at $4^{\circ} \mathrm{C}$ and protein content quantified by Pierce BCA Protein Assay Kit (cat no. 23227; Thermo Fisher Scientific), according to manufacturer's protocol. An equal amount $(70 \mu \mathrm{g})$ of total protein was separated by electrophoresis on a $10 \%$ polyacrylamide gel and transferred onto a nitrocellulose membrane. Nonspecific binding sites were blocked with blocking solution [5\% bovine serum albumin in TTBS (Tris buffer, $\mathrm{pH}$

\section{TABLE 2}

Oligonucleotides for real-time polymerase chain reaction

\begin{tabular}{cl}
\hline Gene & \multicolumn{1}{c}{ Sequence $\left(5^{\prime} \rightarrow 3^{\prime}\right)$} \\
\hline $\mathrm{AT}_{1} \mathrm{R}\left(\mathrm{NM} \_030985.4\right)$ & F: CACTTTCCTGGATGTGCTGA \\
& R: CCCAGAAAGCCGTAGAACAG \\
$\mathrm{AT}_{2} \mathrm{R}(\mathrm{NM}$ _007429.5) & F: CTGCTGGGATTGCCTTAATGAA \\
& R: AGCAGATGTTTCTGATTCCAAAGT \\
eNOS (NM_021838.2) & F: TTCTGGCAAGACCGATTACACGACAT \\
& R: AAAGGCGGAGAGGACTTGTCCAAA \\
\hline
\end{tabular}


7.4, containing $10 \mathrm{mM}$ Tris-HCl, $100 \mathrm{mM} \mathrm{NaCl}$, and 0.1\% Tween 20)] for 2 hours at room temperature. Membranes were incubated with specific antibodies overnight at $4^{\circ} \mathrm{C}$. Primary antibodies were: mouse monoclonal anti-eNOS (1:1000, cat. no. 610297; BD Biosciences, San Jose, CA) and rabbit polyclonal anti-phospho-eNOS ${ }^{\text {Ser-1177 }}$ (1:1000, cat. no. 95715; Cell Signaling Technology, Danvers, MA). Membranes were incubated for 2 hours at room temperature with secondary antibodies: goat-anti-Mouse (1:10000, cat. no. 115-035-166; Jackson ImmunoResearch Laboratories Inc., West Grove, PA), and goat-antiRabbit (1:1500, cat. no. 111-035-144; Jackson ImmunoResearch Laboratories Inc.). Membranes were revealed with chemiluminescence (SuperSignal West Pico Chemiluminescent Substrate; Thermo Fisher Scientific), visualized by autoradiography film, quantified by densitometry using the ImageJ program (Wayne Rasband, National Institutes of Health). All membranes were reblotted using a monoclonal antibody anti- $\alpha$ Actin (1:2000; Sigma-Aldrich) as a loading control. Data were normalized to corresponding values of $\alpha$ Actin densitometry. Phosphorylation of endothelial nitric oxide synthase (eNOS) at Ser-1177 was expressed as the ratio of $\mathrm{p}-\mathrm{eNOS}^{\text {Ser-1177 }}$ and total eNOS densitometry.

Statistical Analysis. Data are expressed as mean \pm S.E.M. and $n$ represents the number of animals used in each experiment. Differences between the groups were analyzed by one-way analysis of variance with Tukey-Kramer post-hoc test. Values of $P<0.05$ were considered statistically significant.

\section{Results}

Systolic blood pressure was not modified by either ovariectomy or CEE treatments (Table 3). Uterine weight and serum levels of estrogen were reduced in OVX rats compared with Sham. Both CEE-SD and CEE-LD treatments restored the uterine weight to levels found in Sham. CEE-LD treatment increased estrogen to levels comparable with Sham, groups, whereas the CEE-SD induced a 3.5 -fold increase in serum estrogen levels (Table 3).

In venular bed, $10 \mu \mathrm{M}$ Ang-II induced contractions in all groups (Fig. 1A). Contractile response to $10 \mu \mathrm{M}$ Ang-II was higher in OVX compared with Sham. CEE-SD treatment did not modify Ang-II contraction compared with OVX. In contrast, the response induced by $10 \mu \mathrm{M}$ Ang-II in CEE-LD was reduced compared with OVX, and similar to the response observed in Sham (Fig. 1B). In the presence of L-NAME, Ang-II contractions were markedly increased only in Sham and CEE-LD groups (Fig. 1C). L-NAME did not modify Ang-II responses in OVX and CEE-SD, suggesting an attenuation of NO release by Ang-II when estrogen is absent (OVX) or at supraphysiologic concentrations (CEE-SD). The increase in Ang-II responses in OVX was paralleled by a 2-fold increase in the ratio of $\mathrm{AT}_{1} \mathrm{R} /$ angiotensin II receptor type $2\left(\mathrm{AT}_{2} \mathrm{R}\right)(\mathbf{F i g}$. 2C) because of upregulation of $A_{1} R$ (Fig. 2A) and unchanged $\mathrm{AT}_{2} \mathrm{R}$ expression (Fig. 2B). Treatment with CEE-SD restored the ratio of $\mathrm{AT}_{1} \mathrm{R} / \mathrm{AT}_{2} \mathrm{R}$ to levels comparable to Sham, by decreasing $\mathrm{AT}_{1} \mathrm{R}$ expression. On the other hand, CEE-LD treatment led a 2 -fold decrease $\mathrm{AT}_{1} \mathrm{R} / \mathrm{AT}_{2} \mathrm{R}$ in OVX by restoring $\mathrm{AT}_{1} \mathrm{R}$ and inducing a 2-fold increase of $\mathrm{AT}_{2} \mathrm{R}$.

To determine the intrinsic mechanisms that contribute to the altered Ang-II responses observed, we first determined NO production in venular sections by DAF-2 fluorescence. Our results reveal a diminished basal NO production in mesenteric venules by OVX SHR, compared with Sham (Fig. 3, A and B). Treatment of OVX SHR with CEE-SD did not modify venous production of NO compared with OVX; however, CEE-LD treatment increased this parameter to the values observed in Sham (Fig. 3, A and B). We next sought to determine whether a difference in the modulation of eNOS expression/activity could account for the disparity in NO production induced by SD and LD of CEE. We found that although the levels of eNOS protein and gene expression were similar in venules of all groups (Fig. 3C), the degree of eNOS phosphorylation at Serine-1177 was markedly reduced by OVX. Both CEE doses (SD and LD) equally increased eNOS phosphorylation in OVX females to the levels observed in Sham (Fig. 3C). Therefore, the inability of CEE-SD treatment to increase NO levels in venules of OVX SHR may not be dependent on changes of eNOS expression/activity; rather, it may be a consequence of increased NO degradation by $\mathrm{O}_{2}^{-}$.

In this regard, we next determined the effects of SD and LD of CEE on venular ROS generation. Measurements of ROS generation by DHE fluorescence showed an increase of oxidative stress in mesenteric venules by OVX compared with Sham (Fig. 4, A and B). Treatment with CEE-LD decreased DHE fluorescence in OVX to a degree similar to that observed in Sham. In contrast, CEE-SD did not modify DHE fluorescence in OVX (Fig. 4, A and B), suggesting dual dose-dependent effect of estrogen on ROS generation. Incubation of venular sections with polyethylene glycol-superoxide dismutase markedly decreased DHE signal in OVX and CEE-SD, revealing higher $\mathrm{O}_{2}^{-}$levels in these groups. In the OVX group, DHE fluorescence was diminished by apocynin or losartan treatment, an indicative of the contribution of NADPH oxidase and $\mathrm{AT}_{1} \mathrm{R}$ in $\mathrm{O}_{2}^{-}$generation, respectively (Fig. 4D). Interestingly in CEE-SD, ROS generation was also inhibited by L-NAME (Fig. $4 \mathrm{E}$ ), suggesting $\mathrm{O}_{2}^{-}$release by NOS when estrogen is at supraphysiologic levels. In Sham (Fig. 4C) and CEE-LD (Fig. 4F) all treatments were without effect on DHE signal.

We next explored the potential role of estrogen treatments on ERs expression that could correlate with the altered responses on $\mathrm{NO} / \mathrm{O}_{2}^{-}$production Figure 5 we show the results of immunofluorescence analysis that determined the expression of estrogen receptors $\mathrm{ER} \alpha, \mathrm{ER} \beta$, and GPER along the venular wall of female SHR. In these studies, we observed that estrogen withdrawal by OVX was associated to an increased expression of ER $\beta$ and decreased expression of GPER. CEE-LD

TABLE 3

Systolic blood pressure, uterine weight, and serum estrogen levels in female SHR Results are expressed as mean \pm S.E.M. of $5-11$ animals.

\begin{tabular}{lrrrr}
\hline & \multicolumn{1}{c}{ Sham } & \multicolumn{1}{c}{ OVX } & \multicolumn{1}{c}{ CEE-SD } & \multicolumn{1}{c}{ CEE-LD } \\
\hline Systemic blood pressure $(\mathrm{mmHg})$ & $171.3 \pm 3.6$ & $160.6 \pm 3.3$ & $170.3 \pm 2.3$ & $167.5 \pm 1.8$ \\
Uterine weight (mg/cm) & $2.65 \pm 0.1$ & $0.75 \pm 0.1^{*}$ & $2.32 \pm 0.1^{\#}$ & $2.08 \pm 0.2^{\#}$ \\
Estrogen (pg/ml) & $30.1 \pm 1.0$ & $17.52 \pm 1.2^{*}$ & $113.1 \pm 13.3^{* \#}$ & $32.2 \pm 6.9^{\#+}$
\end{tabular}

Statistical significance: $P<0.05$ compared with Sham $(*)$, OVX (\#), or CEE-SD (+) 

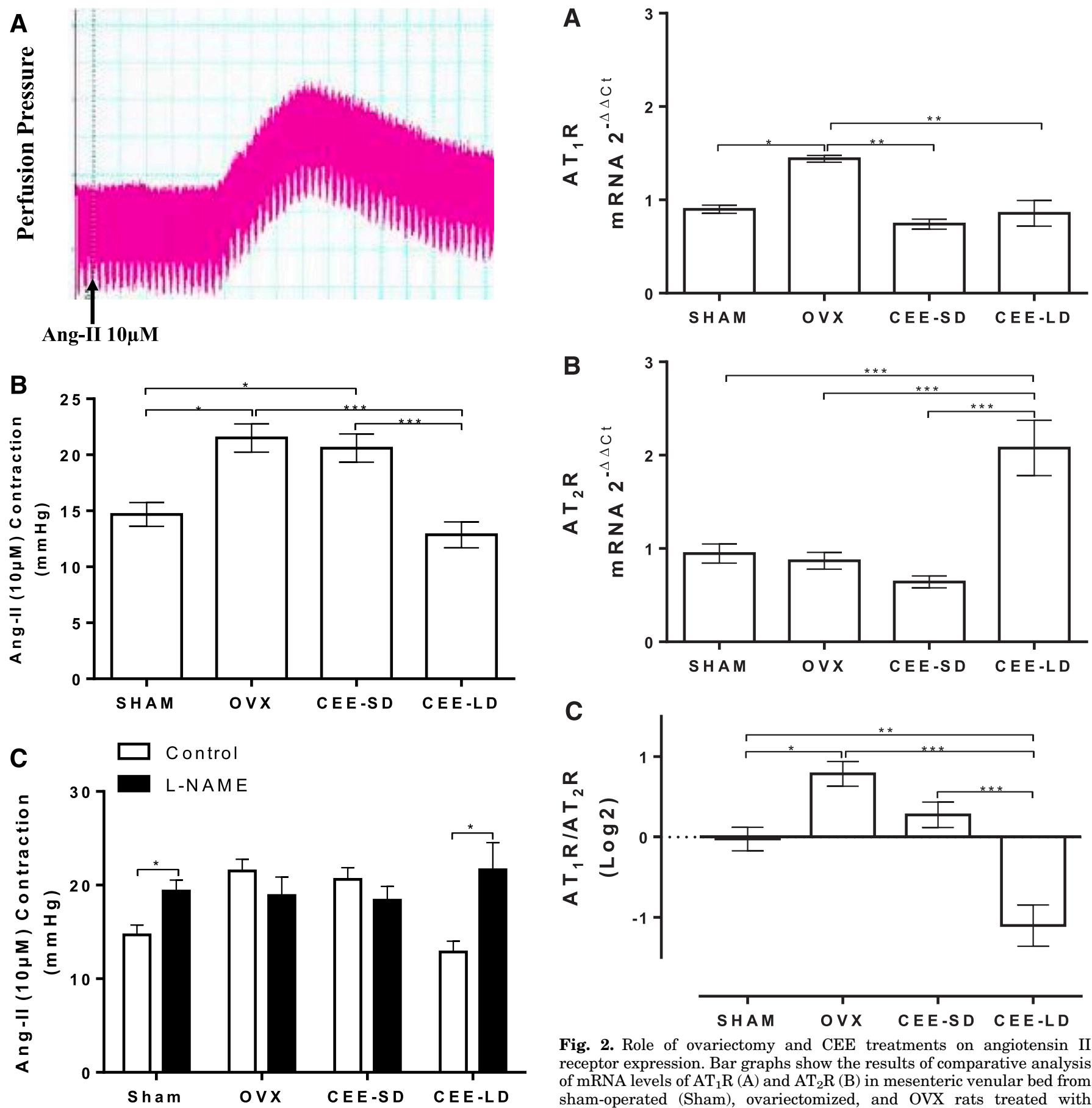

Fig. 2. Role of ovariectomy and CEE treatments on angiotensin II receptor expression. Bar graphs show the results of comparative analysis of mRNA levels of $\mathrm{AT}_{1} \mathrm{R}(\mathrm{A})$ and $\mathrm{AT}_{2} \mathrm{R}(\mathrm{B})$ in mesenteric venular bed from sham-operated (Sham), ovariectomized, and OVX rats treated with conjugated equine estrogens at standard and low dosages. mRNA levels are expressed as $2^{-\Delta \Delta \mathrm{Ct}}$ using $\beta$-actin mRNA as internal control and Sham as reference group. (C) The ratios of $A_{1} T_{1} / A_{2} R$ mRNA expression in each animal are expressed as $\log 2$. Data represent the mean \pm S.E.M. derived from six independent experiments. $* P<0.05$, ${ }^{* *} P<0.01$, ${ }^{* * *} P<0.001$ by analysis of variance with Tukey-Kramer post-hoc test. $(100 \mu \mathrm{M})(\mathrm{C})$. Contractile responses were obtained in mesenteric venular bed from sham-operated (Sham), ovariectomized, and OVX rats treated with conjugated equine estrogens at standard and low dosages. Each point represents mean \pm S.E.M. from six to eight independent experiment. ${ }^{*} P<0.05,{ }^{* * *} P<0.001$ by analysis of variance with Tukey-Kramer posthoc test.

restored ER $\beta$ and GPER expression in OVX to levels observed in Sham. Although CEE-SD restored GPER, it further increased $\mathrm{ER} \beta$ in venules of OVX SHR. No changes in $\mathrm{ER} \alpha$ expression were observed.

\section{Discussion}

This is the first study describing the effects of standard and low dose estrogen treatment in venular function. The basis of our study was the evidence that standard dose of CEE has been associated with increased risk of venous thrombosis in menopausal women. Although regimens using lower doses of estrogen have been recommended to improve risk/benefits of 

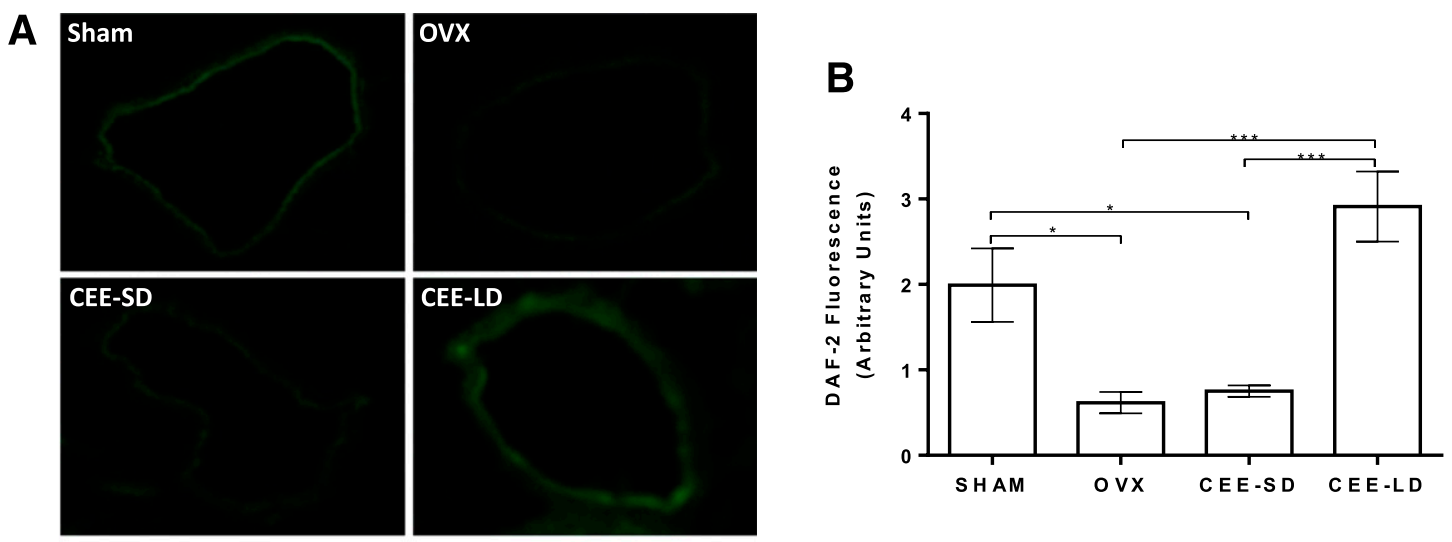

C
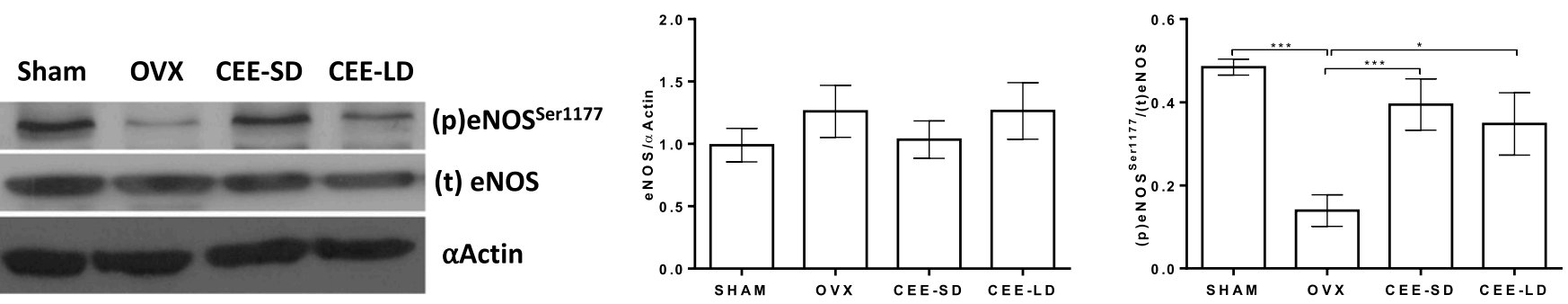

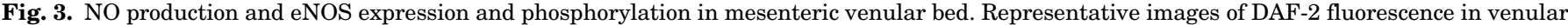

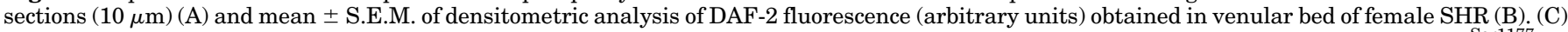

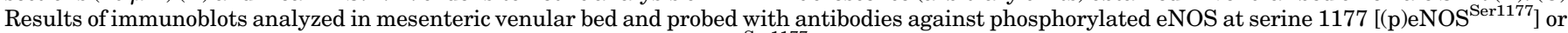

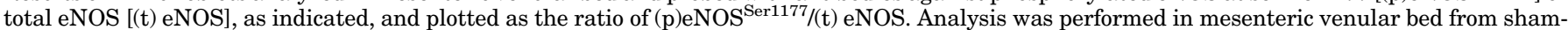

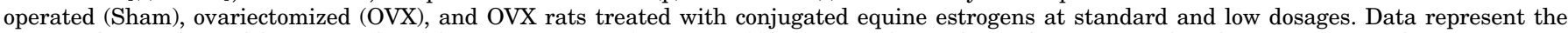
mean \pm S.E.M. derived from six independent experiments. $* P<0.05$, $* * * P<0.001$ by analysis of variance with Tukey-Kramer post-hoc test.

hormone therapy in the postmenopausal period (Santen, 2015), the dose-effect relationship in venous function was largely unknown. In this study, CEE-SD treatment in OVX led to supraphysiologic estradiol concentrations, whereas CEE-LD treatment resulted in similar serum estradiol concentrations than Sham. The different levels of circulating estrogens were associated with opposing effects of CEE-SD and CEE-LD on venular responses to Ang-II, and were in correlation with differential regulation of $\mathrm{NO} / \mathrm{O}_{2}^{-}$systems.

In the present study, we found that ovariectomy markedly increased Ang-II venular contractions, an effect that was improved by treatment with low doses of CEE but was not modified when CEE was administrated at standard doses. Inhibition of NOS by L-NAME led to an increase in Ang-IIinduced contraction in the venular bed from Sham levels ( $\sim 32 \%$ increase in the maximal contraction) and CEE-LD levels $(\sim 68 \%)$. On the other hand, L-NAME induced no changes in the contractile responses to Ang-II when estrogen levels were low (i.e., OVX) or at supraphysiologic levels (i.e., CEE-SD). These data clearly establish a difference in the contribution of NO attenuation of Ang-II contractile responses in the venular bed that prevails when estrogen is at physiologic concentration.

Two major cell surface G-protein-coupled receptor subtypes trigger vascular actions of Ang-II. Most of the detrimental effects of Ang-II are mediated by stimulation of $\mathrm{AT}_{1} \mathrm{R}$, whereas actions by $\mathrm{AT}_{2} \mathrm{R}$ are known to compensate for vascular effects by $\mathrm{AT}_{1} \mathrm{R}$ (Touyz and Schiffrin, 2000). We have previously demonstrated that estrogen modulates Ang-II receptor subtypes in the arterial bed of female SHR (Silva-Antonialli et al., 2004). Interestingly, we observed differences in the regulation of these receptors depending on the type of estrogen used and the serum estradiol concentration reached by each therapeutic regimen. When OVX SHR were treated with a regimen that led to a more physiologic concentration of estradiol (i.e., subcutaneous pellet of $50 \mu \mathrm{g} 17 \beta$-estradiol), we observed a ratio of $\mathrm{AT}_{1} \mathrm{R} / \mathrm{AT}_{2} \mathrm{R}$ in aortas and mesenteric arteries lower that in arteries from untreated OVX SHR (Silva-Antonialli et al., 2004). In opposition, when OVX SHR were treated with standard doses of CEE, reaching supraphysiologic levels of estradiol in the serum, we saw no differences in arterial expression of both $\mathrm{AT}_{1} \mathrm{R}$ and $\mathrm{AT}_{2} \mathrm{R}$ (Costa et al., 2015). In the present study, the greater venous constriction by Ang-II in OVX was paralleled by an increase in $\mathrm{AT}_{1} \mathrm{R}$ expression. Treatment with low dose of CEE diminished $\mathrm{AT}_{1} \mathrm{R}$ expression and concomitantly increased $\mathrm{AT}_{2} \mathrm{R}$ in venules of OVX rats, an effect that was associated with a marked decrease in Ang-II contractions. Nevertheless, even though treatment with standard doses of CEE had decreased $\mathrm{AT}_{1} \mathrm{R}$ expression in the mesenteric venular bed of OVX, we did not see any change in Ang-II-induced vasoconstriction, suggesting that treatment with CEE-SD modulates intrinsic molecular mechanisms that contribute to maintenance of Ang-II hypercontractility.

The favorable effects of estrogen on vascular function have been largely associated with regulation of NO production by mechanisms that involve genomic upregulation of the expression of the endothelial isoform of NOS (eNOS) (Goetz et al., 1994; Weiner et al., 1994). Nevertheless, most of the benefits of estrogen therapy on eNOS were described in the arterial bed (Chambliss and Shaul, 2002), although little is known about how estrogen therapies affect venular NO generation. In OVX SHR, we found an important disparity in the modulation of 
A
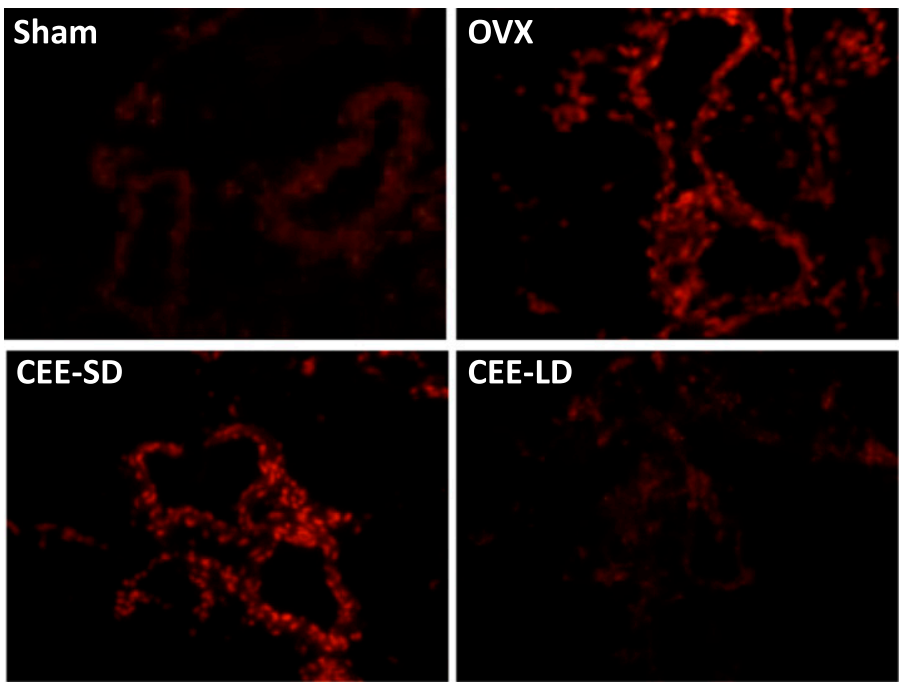

CEE-LD

C

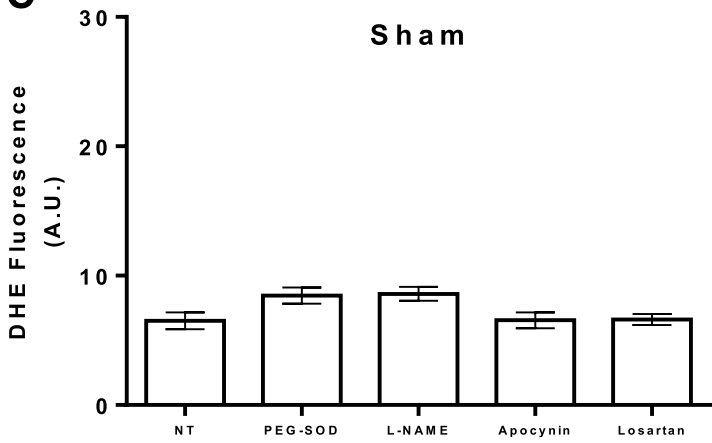

D

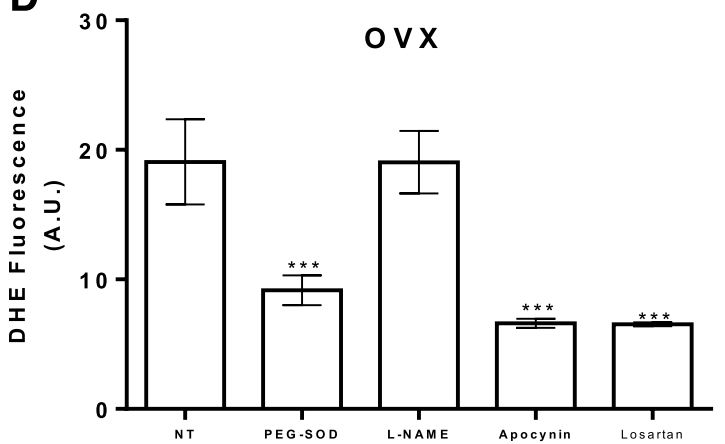

E

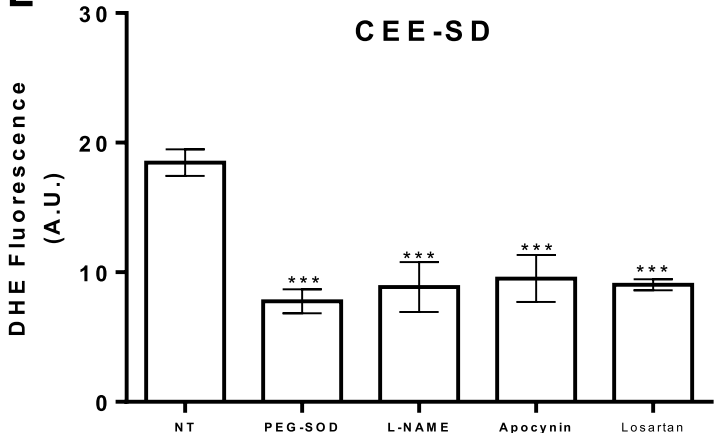

F
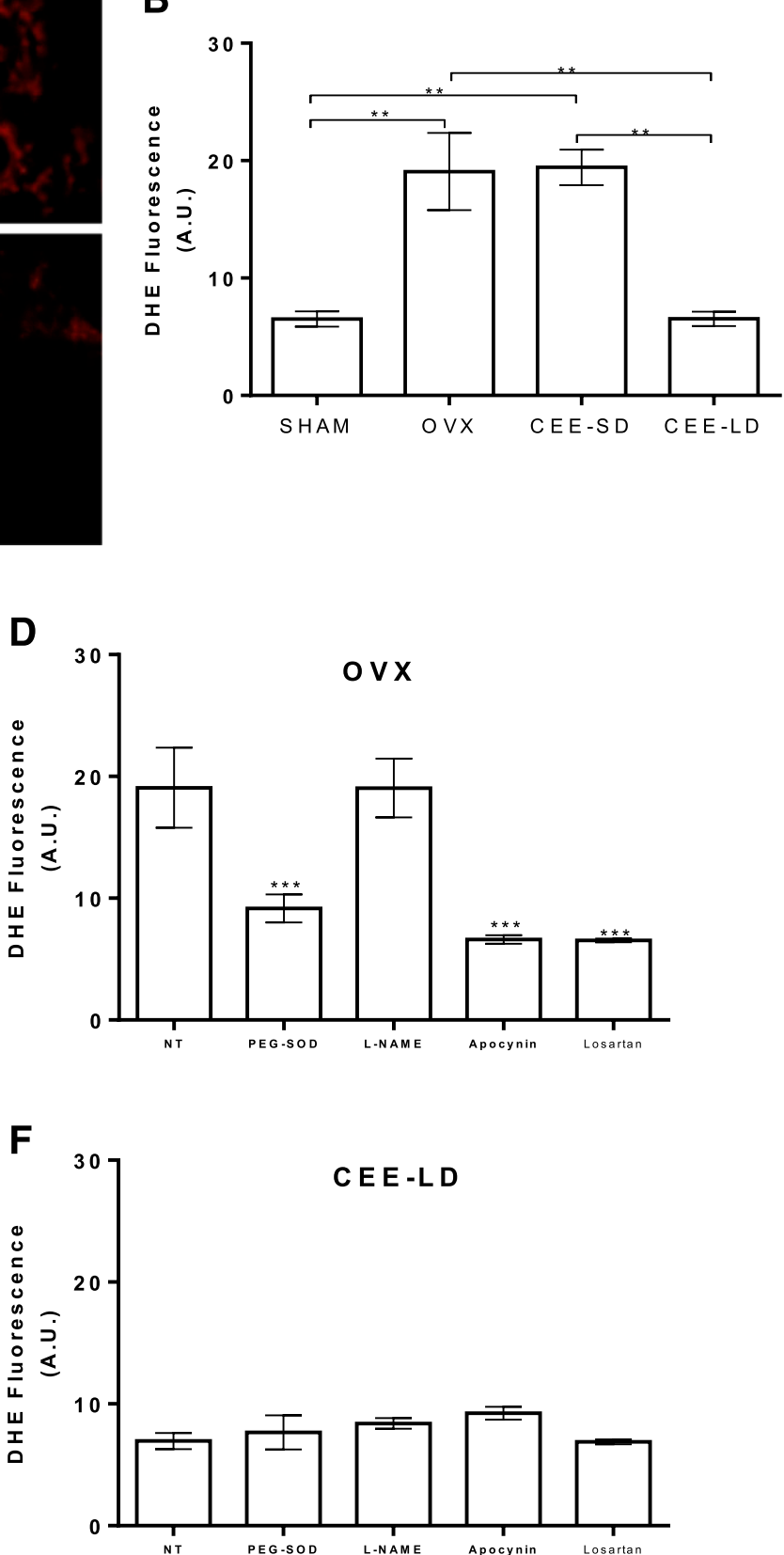

Fig. 4. Reactive oxygen species (ROS) generation. Shown are representative fluorescent images of nuclei labeled with ethidium bromide produced by oxidation of DHE by ROS (A). Bar graphs show the results of densitometric analyses of fluorescence intensity expressed as arbitrary units of vehicletreated venular sections (B) from sham-operated (Sham), ovariectomized (OVX), and OVX rats treated with conjugated equine estrogens (CEE) at standard (CEE-SD) and low (CEE-LD) dosages; as well as in venular sections of Sham (C), OVX (D), CEE-SD (E), and CEE-LD (F) following 30-minute treatment with permeable superoxide dismutase (150 IU/ml); with NOS inhibitor (L-NAME, $100 \mu \mathrm{M}$ ), NADPH-oxidase inhibitor (apocynin, $10 \mathrm{mM}$ ), and $\mathrm{AT}_{1} \mathrm{R}$ blocker (losartan, $1 \mu \mathrm{M}$ ). Data represent the mean \pm S.E.M. derived from six independent experiments. $* * P<0.01$, $* * * P<0.001$ by analysis of variance with Tukey-Kramer post-hoc test.

venular NO bioavailability by standard and low doses of CEE. We observed that NO production and eNOS phosphorylation were decreased in OVX, and that low dose CEE restored this parameter. However, the standard dose of CEE did not modify NO bioavailability compared with OVX, despite its ability to promote eNOS phosphorylation. Therefore, we hypothesized that CEE-SD is ineffective in modifying $\mathrm{NO}$ availability in
OVX, not because it lacks the ability to modulate NO release, but above all because it increases NO degradation after synthesis.

It is well established that the biologic activity of NO is modified by $\mathrm{ROS}$ such as $\mathrm{O}_{2}^{-}$. Increased $\mathrm{O}_{2}^{-}$concentration in the vasculature results in rapid scavenging of $\mathrm{NO}$ and a decrease in its bioavailability (Touyz, 2003). In previous studies, we 
ER- $\alpha$

Sham
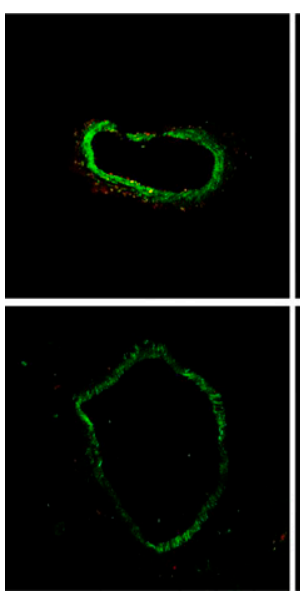

CEE-SD ovx
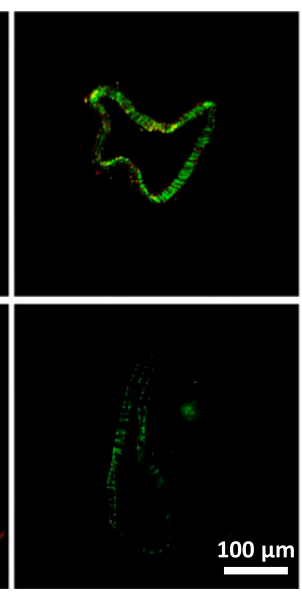

CEE-LD
ER- $\beta$

Sham
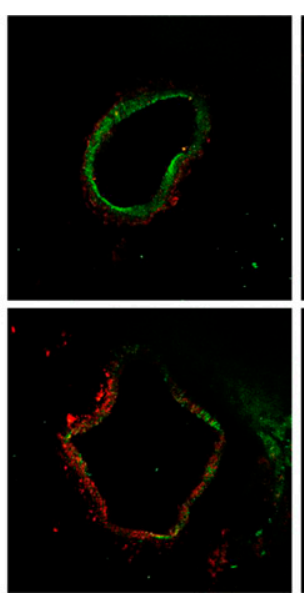

CEE-SD ovx
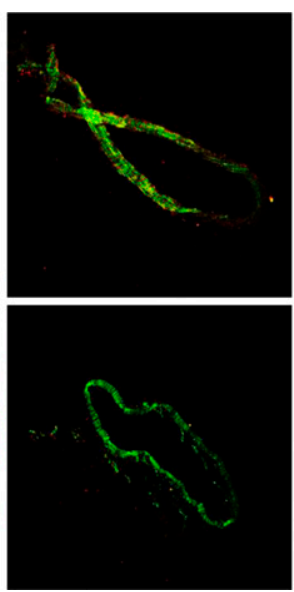

CEE-LD
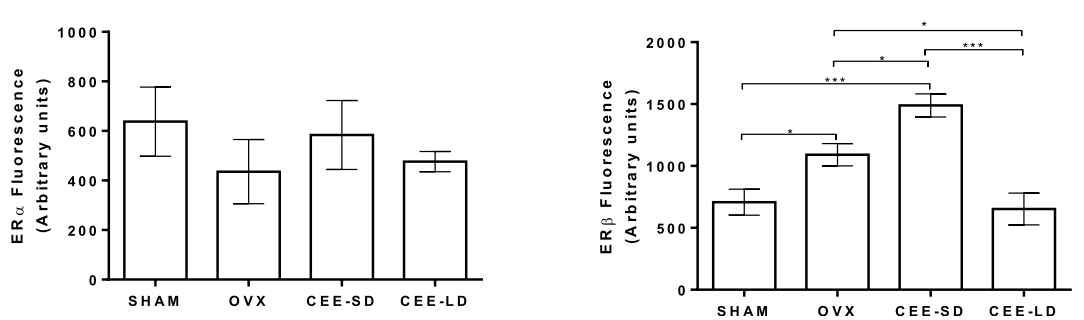

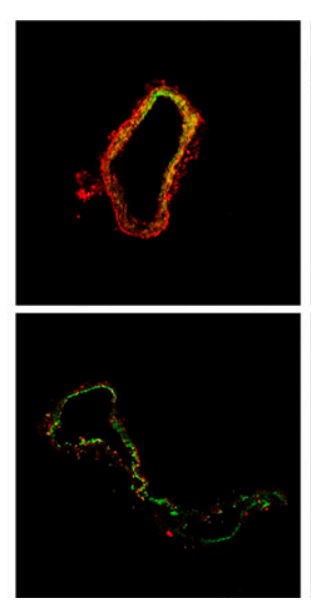

CEE-SD ovx

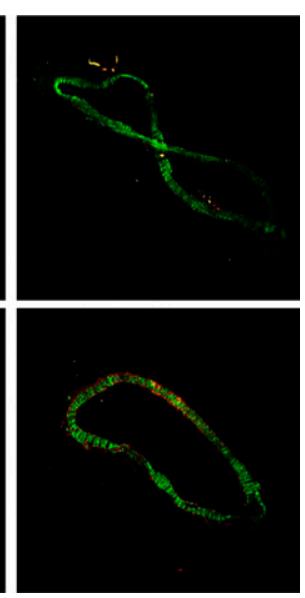

CEE-LD

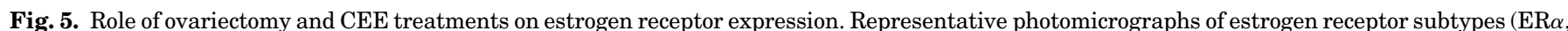

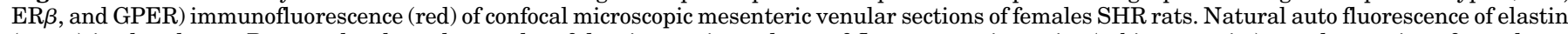

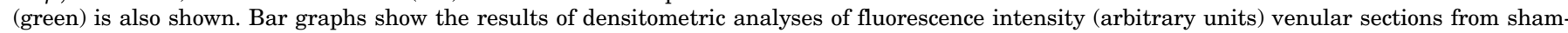

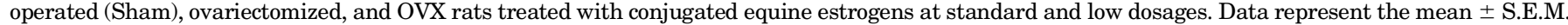
derived from six independent experiments. $* P<0.05$, $* * * P<0.001$ by analysis of variance with Tukey-Kramer post-hoc test.

have shown that CEE-SD treatment reduces ROS production in the arterial bed of OVX SHR by downregulating pro-oxidant and increasing antioxidant enzyme expression, which improves endothelial function (Ceravolo et al., 2013; Costa et al., 2015). Contrary to that, CEE-SD does not decrease $\mathrm{O}_{2}^{-}$ generation in the venular bed of the same menopause model, revealing a differential regulation of $\mathrm{NO}_{2}^{-}$systems by estrogens in arteries and veins.

It has been shown that Ang-II increases $\mathrm{O}_{2}^{-}$production in different arterial beds via $\mathrm{AT}_{1} \mathrm{R}$-dependent and $\mathrm{NADPH}$ oxidase-mediated signaling pathways (Griendling et al., 1994; Schramm et al., 2012). Angiotensin-II regulates the expression and activity subunit of NADPH (Nox) via $\mathrm{AT}_{1} \mathrm{R}$ in vivo. Infusion of Ang-II induced a significant increase in blood pressure, accompanied by augmented expression of Nox1 mRNA and $\mathrm{O}_{2}^{-}$production in aortas of Nox1 wild-type mice, whereas the elevation in blood pressure and production of $\mathrm{O}_{2}^{-}$were significantly blunted in Nox1 knockouts (Matsuno et al., 2005). In agreement with our previous studies of the mesenteric arterial bed (Dantas et al., 2002), our present data show that $\mathrm{O}_{2}^{-}$overproduction in mesenteric venules of OVX SHR is lessened by the blockage of $\mathrm{AT}_{1} \mathrm{R}$ with losartan and by inhibition of NADPH-oxidase activity with apocynin. However, contrary to what was seen in the arterial bed (Ceravolo et al., 2013), treatment with CEE-SD did not decrease $\mathrm{AT}_{1} \mathrm{R}$ and $\mathrm{NADPH}$-derived $\mathrm{O}_{2}^{-}$production in venules and, moreover, facilitates $\mathrm{O}_{2}^{-}$generation via eNOS, as evidenced by decreased DHE fluorescence after L-NAME inhibition. Under normal conditions, the primary product of eNOS activation is NO, which produces beneficial effects on vascular biology. There is evidence, however, that in certain pathophysiological conditions when there is a depletion of important molecules essential for NO production (e.g., tetrahydrobiopterin, L-arginine) eNOS becomes increasingly "uncoupled" from NO production and produces $\mathrm{O}_{2}^{-}$(White et al., 2010). Although studies suggest that such conditions as aging and the presence of cardiovascular risk factors can modify the effects of estrogen on NO production owing to disarrangement of eNOS (White et al., 2010; Murphy, 2011), there is no data describing the direct effect of estrogen regimens and doses on eNOS uncoupling. Unfortunately, in our studies a few limitations (amount of tissue, assay sensitivity) did not allow us to better characterize the role of estrogens in eNOS uncoupling in veins. Nevertheless, our results on L-NAME inhibition of $\mathrm{O}_{2}^{-}$production bring new insight into the potential detrimental mechanisms of supraphysiologic doses of CEE.

Vascular estrogen actions are mediated by two members of the nuclear receptor superfamily $(\operatorname{ER} \alpha$ and $\operatorname{ER} \beta)$ and by a GPER. ER $\alpha$ has been described as the key player on cardiovascular protection by estrogen, although insufficient and controversial information is available on the contribution of $\mathrm{ER} \beta$ and GPER (Meyer and Barton, 2009). $\mathrm{ER} \alpha$ is known to 
upregulate eNOS expression (Sumi and Ignarro, 2003) and activates the enzyme via Ser-1177 phosphorylation (Tarhouni et al., 2013). However, recent evidence has recognized that GPER activation results in the rapid mobilization of intracellular calcium and activation of eNOS via Akt-mediated signaling pathway (Meyer et al., 2011). In our studies, we saw no changes in ER $\alpha$ expression in veins of OVX or CEEtreated rats. Instead, we found a major regulation of GPER expression by OVX and estrogen treatments. Our study is the first to describe that GPER expression in veins is decreased by estrogen withdrawal, and that chronic treatment with CEE restores GPER expression. Interestingly, changes in eNOS phosphorylation by OVX and CEE treatments were paralleled by variations in GPER expression in the venular wall.

Although this parallelism with GPER is a plausible explanation for the effects of CEE on eNOS phosphorylation, it does not correlate with the differences in $\mathrm{NO}$ bioavailability and $\mathrm{O}_{2}^{-}$ production observed after treatment with low and standard doses of CEE. Interestingly, previous studies have shown that GPER can be associated with cardiovascular damage and increased $\mathrm{O}_{2}^{-}$production in aged females (Meyer et al., 2016). Moreover, in primary vascular smooth muscle cells from GPER knockout mice, the Ang-II-stimulating effect on $\mathrm{O}_{2}^{-}$ generation was completely absent (Meyer et al., 2016). In contrast, we found a marked difference in $\operatorname{ER} \beta$ expression in the venular wall could better correlate with $\mathrm{O}_{2}^{-}$production. OVX induces an increase of $\mathrm{ER} \beta$ expression that was corrected by CEE-LD, but not CEE-SD. In fact, the degree of $\operatorname{ER} \beta$ expression after CEE-SD treatment was considerably higher than the levels observed in OVX. The mechanisms to explain how the imbalance in ER ratio can modify estrogen effects are largely unknown, but recent studies have interestingly revealed that $\mathrm{ER} \beta$ exhibits an inhibitory action on $\mathrm{ER} \alpha$-dependent gene expression and may oppose the actions of $\operatorname{ER} \alpha$ (Matthews and Gustafsson, 2003; Bhavnani et al., 2008)

Taken together our data have established that CEE may display opposite effects in the venular function when administrated at standard or lower dose. Although treatment of OVX SHR with CEE-LD has a beneficial venular effect by increasing NO bioavailability and improving vascular responses to Ang-II, CEE-SD does not modify the detriment induced by OVX. Although CEE-SD is as effective in activating eNOS phosphorylation as CEE-LD, this treatment does not improve NO bioavailability, because it maintains higher $\mathrm{O}_{2}^{-}$production. Increased risk of vein thrombosis is the major vascular complication during HT and has been largely associated with increased risk of cardiovascular disease in postmenopausal women. These results improve our knowledge of cardiovascular modulation by estrogen and establish that dose regimen significantly affects the direct estrogen-mediated effects on vascular function, which may influence the risk/benefit assessment of HT with respect to cardiovascular events and other outcomes via multiple pathways.

\section{Acknowledgments}

The authors are grateful to Marta Rodrigues and Sônia Maria Leite for technical support.

\section{Authorship Contributions}

Participated in research design: Araujo, Akamine, Vila, Dantas, Ceravolo, Carvalho.
Conducted experiments: Araujo, Costa, Echem, Oliveira, SantosEichler, Colli, Jimenéz-Altayó.

Contributed new reagents or analytic tools: Araujo, Carvalho, Ceravolo, Dantas.

Performed data analysis: Araujo, Costa, Echem, Oliveira, SantosEicheler, Jiménez-Altayó, Vila, Akamine, Dantas, Ceravolo, Carvalho.

Wrote or contributed to the writing of the manuscript: Araujo, Costa, Echem, Oliveira, Santos-Eichler, Colli, Jiménez-Altayó, Vila, Akamine, Dantas, Ceravolo, Carvalho.

\section{References}

Barton M and Meyer MR (2009) Postmenopausal hypertension: mechanisms and therapy. Hypertension 54:11-18.

Barton M, Meyer MR, and Haas E (2007) Hormone replacement therapy and ath erosclerosis in postmenopausal women: does aging limit therapeutic benefits? Arterioscler Thromb Vasc Biol 27:1669-1672.

Beral V and Collaborators MWS; Million Women Study Collaborators (2003) Breast cancer and hormone-replacement therapy in the Million Women Study. Lancet 362:419-427.

Bhavnani BR, Tam SP, and Lu X (2008) Structure activity relationships and differential interactions and functional activity of various equine estrogens mediated via estrogen receptors (ERs) ERalpha and ERbeta. Endocrinology 149:4857-4870.

Blondon M, van Hylckama Vlieg A, Wiggins KL, Harrington LB, McKnight B, Rice KM, Rosendaal FR, Heckbert SR, Psaty BM, and Smith NL (2014) Differential associations of oral estradiol and conjugated equine estrogen with hemostatic biomarkers. J Thromb Haemost 12:879-886.

Ceravolo GS, Filgueira FP, Costa TJ, Lobato NS, Chignalia AZ, Araujo PX, Tostes RC, Dantas AP, Fortes ZB, and Carvalho MH (2013) Conjugated equine estrogen treatment corrected the exacerbated aorta oxidative stress in ovariectomized spontaneously hypertensive rats. Steroids 78:341-346.

Ceravolo GS, Franco MC, Carneiro-Ramos MS, Barreto-Chaves ML, Tostes RC, Nigro D, Fortes ZB, and Carvalho MH (2007) Enalapril and losartan restored blood pressure and vascular reactivity in intrauterine undernourished rats. Life Sci $\mathbf{8 0}$ : $782-787$.

Chambliss KL and Shaul PW (2002) Estrogen modulation of endothelial nitric oxide synthase. Endocr Rev 23:665-686.

Christiansen C, Christensen MS, McNair P, Hagen C, Stocklund KE, and Transbøl I (1980) Prevention of early postmenopausal bone loss: controlled 2-year study in 315 normal females. Eur J Clin Invest 10:273-279.

Cora MC, Kooistra L, and Travlos G (2015) Vaginal cytology of the laboratory rat and mouse: review and criteria for the staging of the estrous cycle using stained vaginal smears. Toxicol Pathol 43:776-793.

Costa TJ, Ceravolo GS, dos Santos RA, de Oliveira MA, Araújo PX, Giaquinto LR, Tostes RC, Akamine EH, Fortes ZB, Dantas AP, et al. (2015) Association of testosterone with estrogen abolishes the beneficial effects of estrogen treatment by increasing ROS generation in aorta endothelial cells. Am J Physiol Heart Circ Physiol 308:H723-H732.

Dantas AP, Scivoletto R, Fortes ZB, Nigro D, and Carvalho MH (1999) Influence of female sex hormones on endothelium-derived vasoconstrictor prostanoid generation in microvessels of spontaneously hypertensive rats. Hypertension 34:914-919.

Dantas AP, Tostes RC, Fortes ZB, Costa SG, Nigro D, and Carvalho MH (2002) In vivo evidence for antioxidant potential of estrogen in microvessels of female spontaneously hypertensive rats. Hypertension 39:405-411.

Files JA, Ko MG, and Pruthi S (2011) Bioidentical hormone therapy. Mayo Clin Proc 86:673-680, quiz 680 .

Fortepiani LA, Zhang H, Racusen L, Roberts, 2nd LJ, and Reckelhoff JF (2003) Characterization of an animal model of postmenopausal hypertension in spontaneously hypertensive rats. Hypertension 41:640-645.

Gambacciani M, Cappagli B, Ciaponi M, Pepe A, Vacca F, and Genazzani AR (2008) Ultra low-dose hormone replacement therapy and bone protection in postmenopausal women. Maturitas 59:2-6.

Gambacciani M, Ciaponi M, Cappagli B, and Genazzani AR (2001) Effects of low-dose continuous combined conjugated estrogens and medroxyprogesterone acetate on menopausal symptoms, body weight, bone density, and metabolism in postmenopausal women. Am J Obstet Gynecol 185:1180-1185.

Gambacciani M, Ciaponi M, Cappagli B, Monteleone P, Benussi C, Bevilacqua G, and Genazzani AR (2003a) Effects of low-dose, continuous combined estradiol and noretisterone acetate on menopausal quality of life in early postmenopausal women. Maturitas 44:157-163.

Gambacciani M, Ciaponi M, Cappagli B, Monteleone P, Benussi C, Bevilacqua G, and Genazzani AR (2003b) Postmenopausal femur bone loss: effects of a low dose hormone replacement therapy. Maturitas 45:175-183.

Goetz RM, Morano I, Calovini T, Studer R, and Holtz J (1994) Increased expression of endothelial constitutive nitric oxide synthase in rat aorta during pregnancy. Biochem Biophys Res Commun 205:905-910.

González Ordóñez AJ, Fernández Carreira JM, Medina Rodríguez JM, Martín Sánchez L, Alvarez Díaz R, Alvarez Martinez MV, and Coto Garcia E (2000) Risk of venous thromboembolism associated with the insertion/deletion polymorphism in the angiotensin-converting enzyme gene. Blood Coagul Fibrinolysis 11:485-490.

Griendling KK, Minieri CA, Ollerenshaw JD, and Alexander RW (1994) Angiotensin II stimulates NADH and NADPH oxidase activity in cultured vascular smooth muscle cells. Circ Res 74:1141-1148.

Grodstein F, Manson JE, Colditz GA, Willett WC, Speizer FE, and Stampfer MJ (2000) A prospective, observational study of postmenopausal hormone therapy and primary prevention of cardiovascular disease. Ann Intern Med 133:933-941. 
Hale GE and Shufelt CL (2015) Hormone therapy in menopause: An update on cardiovascular disease considerations. Trends Cardiovasc Med 25:540-549.

Horsman A, Jones M, Francis R, and Nordin C (1983) The effect of estrogen dose on postmenopausal bone loss. N Engl J Med 309:1405-1407.

Jimenez-Altayo F, Caracuel L, Perez-Asensio FJ, Martinez-Revelles S, Messeguer A Planas AM, and Vila E (2009) Participation of oxidative stress on rat middle cerebral artery changes induced by focal cerebral ischemia: beneficial effects of 3,4 dihydro-6-hydroxy-7-methoxy-2,2-dimethyl-1(2H)-benzopyran (CR-6). J Pharmacol Exp Ther 331:429-436.

Hu FB and Grodstein F (2002) Postmenopausal hormone therapy and the risk of cardiovascular disease: the epidemiologic evidence. Am J Cardiol 90 (1A):26F-29F

Lindsay R (1993) Criteria for successful estrogen therapy in osteoporosis. Osteoporosis Int 3(suppl 2):9-12; discussion 12-13.

Lindsay R, Gallagher JC, Kleerekoper M, and Pickar JH (2002) Effect of lower doses of conjugated equine estrogens with and without medroxyprogesterone acetate on bone in early postmenopausal women. JAMA 287:2668-2676.

Lindsay R, Hart DM, and Clark DM (1984) The minimum effective dose of estrogen for prevention of postmenopausal bone loss. Obstet Gynecol 63:759-763.

Loiola RA, Fernandes L, Eichler R, Passaglia RdeC, Fortes ZB, and de Carvalho MH (2011) Vascular mechanisms involved in angiotensin II-induced venoconstriction in hypertensive rats. Peptides 32:2116-2121.

Matsuno K, Yamada H, Iwata K, Jin D, Katsuyama M, Matsuki M, Takai S, Yamanishi K, Miyazaki M, Matsubara H, et al. (2005) Nox1 is involved in angiotensin II-mediated hypertension: a study in Nox1-deficient mice. Circulation 112 2677-2685.

Matthews J and Gustafsson JA (2003) Estrogen signaling: a subtle balance between ER alpha and ER beta. Mol Interv 3:281-292.

Meyer MR and Barton M (2009) ERalpha, ERbeta, and gpER: novel aspects of oestrogen receptor signalling in atherosclerosis. Cardiovasc Res 83:605-610.

Meyer MR, Fredette NC, Daniel C, Sharma G, Amann K, Arterburn JB, Barton M, and Prossnitz ER (2016) Obligatory role for GPER in cardiovascular aging and disease. Sci Signal 9:ra105.

Meyer MR, Prossnitz ER, and Barton M (2011) The G protein-coupled estrogen receptor GPER/GPR30 as a regulator of cardiovascular function. Vascul Pharmacol 55:17-25.

Mogielnicki A, Chabielska E, Pawlak R, Szemraj J, and Buczko W (2005) Angiotensin II enhances thrombosis development in renovascular hypertensive rats. Thromb Haemost 93:1069-1076.

Murphy E (2011) Estrogen signaling and cardiovascular disease. Circ Res 109: 687-696

Novensà L, Novella S, Medina P, Segarra G, Castillo N, Heras M, Hermenegildo C, and Dantas AP (2011) Aging negatively affects estrogens-mediated effects on nitric oxide bioavailability by shifting $\mathrm{ER} \alpha / \mathrm{ER} \beta$ balance in female mice. PLoS One 6 e25335.

Peeyananjarassri K and Baber R (2005) Effects of low-dose hormone therapy on menopausal symptoms, bone mineral density, endometrium, and the cardiovascular system: a review of randomized clinical trials. Climacteric 8:13-23.

Pfaffl MW (2001) A new mathematical model for relative quantification in real-time RT-PCR. Nucleic Acids Res 29:e45.

Pinto S, Virdis A, Ghiadoni L, Bernini G, Lombardo M, Petraglia F, Genazzani AR, Taddei S, and Salvetti A (1997) Endogenous estrogen and acetylcholine-induced vasodilation in normotensive women. Hypertension 29:268-273.

Rossouw JE, Anderson GL, Prentice RL, LaCroix AZ, Kooperberg C, Stefanick ML, Jackson RD, Beresford SA, Howard BV, Johnson KC, et al.; Writing Group for the Women's Health Initiative Investigators (2002) Risks and benefits of estrogen plus progestin in healthy postmenopausal women: principal results From the Women's Health Initiative randomized controlled trial. JAMA 288:321-333.

Santen RJ (2015) Vaginal administration of estradiol: effects of dose, preparation and timing on plasma estradiol levels. Climacteric 18:121-134.

Sarrel P, Dobay B, and Wiita B (1998) Estrogen and estrogen-androgen replacement in postmenopausal women dissatisfied with estrogen-only therapy. Sexual behavior and neuroendocrine responses. J Reprod Med 43:847-856.
Schramm A, Matusik P, Osmenda G, and Guzik TJ (2012) Targeting NADPH oxidases in vascular pharmacology. Vascul Pharmacol 56:216-231.

Senchenkova EY, Russell J, Esmon CT, and Granger DN (2014) Roles of Coagulation and fibrinolysis in angiotensin II-enhanced microvascular thrombosis. Microcirculation 21:401-407.

Silva-Antonialli MM, Tostes RC, Fernandes L, Fior-Chadi DR, Akamine EH, Carvalho $\mathrm{MH}$, Fortes ZB, and Nigro D (2004) A lower ratio of AT1/AT2 receptors of angiotensin II is found in female than in male spontaneously hypertensive rats. Cardiovasc Res 62:587-593.

Smith NL, Blondon M, Wiggins KL, Harrington LB, van Hylckama Vlieg A, Floyd JS, Hwang M, Bis JC, McKnight B, Rice KM, et al (2014) Lower risk of cardiovascular events in postmenopausal women taking oral estradiol compared with oral conjugated equine estrogens. JAMA Intern Med 174:25-31

Speroff L (2010) Transdermal hormone therapy and the risk of stroke and venous thrombosis. Climacteric 13:429-432.

Steinkellner AR, Denison SE, Eldridge SL, Lenzi LL, Chen W, and Bowlin SJ (2012) A decade of postmenopausal hormone therapy prescribing in the United States: long-term effects of the Women's Health Initiative. Menopause 19:616-621.

Sumi D and Ignarro LJ (2003) Estrogen-related receptor alpha 1 up-regulates endothelial nitric oxide synthase expression. Proc Natl Acad Sci USA 100:1445114456.

Tarhouni K, Guihot AL, Freidja ML, Toutain B, Henrion B, Baufreton C, Pinaud F, Procaccio V, Grimaud L, Ayer A, et al. (2013) Key role of estrogens and endothelia estrogen receptor $\alpha$ in blood flow-mediated remodeling of resistance arteries. Arterioscler Thromb Vasc Biol 33:605-611.

The Writing Group for the PEPI Trial (1995) Effects of estrogen or estrogen/progestin regimens on heart disease risk factors in postmenopausal women. The Postmenopausal Estrogen/Progestin Interventions (PEPI) Trial. JAMA 273:199-208.

Touyz RM (2003) Reactive oxygen species in vascular biology: role in arterial hypertension. Expert Rev Cardiovasc Ther 1:91-106.

Touyz RM and Schiffrin EL (2000) Signal transduction mechanisms mediating the physiological and pathophysiological actions of angiotensin II in vascular smooth muscle cells. Pharmacol Rev 52:639-672.

Virdis A, Ghiadoni L, Pinto S, Lombardo M, Petraglia F, Gennazzani A, Buralli S, Taddei S, and Salvetti A (2000) Mechanisms responsible for endothelial dysfunction associated with acute estrogen deprivation in normotensive women. Circulation 101:2258-2263.

Warner TD (1990) Simultaneous perfusion of rat isolated superior mesenteric arterial and venous beds: comparison of their vasoconstrictor and vasodilator responses to agonists. Br J Pharmacol 99:427-433.

Weiner CP, Lizasoain I, Baylis SA, Knowles RG, Charles IG, and Moncada S (1994) Induction of calcium-dependent nitric oxide synthases by sex hormones. Proc Natl Acad Sci USA 91:5212-5216.

White RE, Gerrity R, Barman SA, and Han G (2010) Estrogen and oxidative stress: A novel mechanism that may increase the risk for cardiovascular disease in women. Steroids 75:788-793.

Zang H, Shi H, and Speroff L (2010) Low-dose hormone therapy in postmenopausal women in China. Climacteric 13:544-552.

Address correspondence to: Dr. Maria Helena Catelli de Carvalho, Department of Pharmacology, Institute of Biomedical Sciences I, University of Sao Paulo. Av. Prof. Lineu Prestes, 1524. São Paulo, SP. 05508-900, Brazil. mhcarval@icb.usp.br. Dr. Graziela Scalianti Ceravolo, Department of Physiological Sciences, Department of Physiological Sciences, Biological Sciences Center, State University of Londrina, 86057-970, Brazil. gsceravolo@uel.br. Dr. Ana Paula Dantas, Group of Atherosclerosis and Coronary Disease, Institut Clinic Cardiovascular, Institut d'Investigaciones Biomédiques August Pi I Sunyer (IDIBAPS). C. Casanova, 143, Cellex-2A. Barcelona, 08036, Spain. adantas@clinic.ub.es. 